\title{
OS MIGRANTES PESCADORES E OS RASTROS DE COMIDA
}

\author{
Valdir Gregory \\ Nelson de Castro Neto \\ Paola Stefanutti
}

\begin{abstract}
Resumo
O presente artigo refere-se a uma parte de uma pesquisa em que se analisa as memórias de pescadores de Foz do Iguaçu-PR, a partir de 1961, através de suas narrativas sobre vivências e alimentação. Será discutida uma das linhas que derivou desta pesquisa maior, sendo: as migrações e os rastros de comida, que reforçam a identidade do local de origem e/ou étnica. O procedimento metodológico adotado neste trabalho busca interpretar dados obtidos através de narrativas de entrevistas, sendo considerada uma pesquisa oral temática. A abordagem dessa escrita, também encontra respaldo no historiador italiano Carlo Ginzburg, através da micro-história e do método indiciário. São levantados temas sobre migração, memórias e alimentação. Essas reflexões de saberes tradicionais, sabores e predileções, são de fundamental importância para o registro das memórias alimentares dos pescadores. Espera-se ainda contribuir com memórias em Foz do Iguaçu e que as informações e reflexões dessa pesquisa possam fomentar e fundamentar trabalhos futuros sobre migração e alimentação na localidade.
\end{abstract}

Palavras-chave: migração, alimentação, memórias

\begin{abstract}
This paper refers to a part of a research that analyzes the fishermen memories of Foz do Iguaçu-PR, from 1961 through their narratives about experiences and food. One of the lines derived from this greater research will be discussed, as follows: migration and food tracks that reinforce the identity of the place of origin and/or ethnic. The methodological procedure adopted in this paper seeks to interpret data obtained through these narratives, considered thematic oral history research. The writing approach also finds support in the Italian historian Carlo Ginzburg, through microhistory and evidential paradigm. Issues are raised about migration, memories and feed. These reflections of traditional knowledge, tastes and predilections are of fundamental importance for the registration of food memories of fishermen. It is also expected to contribute about memories in Foz do Iguaçu and those information and reflections of this research can foment and support further work on migration and feed in the locality.
\end{abstract}

Keywords: migration, feed, memories 


\section{Introdução}

Esse artigo refere-se a uma parte de uma pesquisa em que se analisa as memórias de pescadores de Foz do Iguaçu, através de suas narrativas sobre vivências e alimentação. Será discutida uma das linhas que derivou desta pesquisa maior, sendo: as migrações e os rastros de comida, que reforçam a identidade do local de origem e/ou étnica.

Essa pesquisa parte do princípio de que os comportamentos alimentares de um determinado grupo não dependem unicamente do fator nutricional e biológico, e que não são limitados apenas pela questão geográfica, mas pelos traços culturais, inclusive étnicos, de influência e de formação, representando suas histórias, seus costumes, crenças e relações que se instauraram, enfatizando um olhar sensível e transdisciplinar para a questão da alimentação.

Nessa linha de pesquisa sobre migração e alimentação serão abordadas reflexões sobre costumes alimentares como indícios pertinentes de análise das relações sociais, a partir de narrativas obtidas em entrevistas. Toma-se Foz do Iguaçu, no Oeste do estado do Paraná, como cenário e, como sujeitos desta pesquisa, seus pescadores, artesanais ou não. Segundo o Ministério da Pesca e Aquicultura (MPA, 2014), a pesca artesanal é considerada uma das atividades econômicas mais tradicionais do país, sendo atividade caracterizada por ser desempenhada por produtores autônomos, em regime de economia familiar ou individual, que abrange a aquisição de alimento para as famílias dos pescadores ou para fins comerciais ${ }^{1}$.

É relevante saber sobre os pescadores, eles que são o primeiro elo da cadeia produtiva do pescado, pensando, portanto, como se dava a relação deles com a comida. Busca-se, nas narrativas deles, saber sobre o que comiam, onde comiam, com quem comiam, métodos de preparo e como era a conexão alimentar com o pescado local. Investigam-se os comportamentos alimentares de pescadores e a relação do peixe com a alimentação. Também se investiga sobre a vida deles sem energia elétrica, a rotina, as pescarias, as dificuldades, as relações sociais, o comércio e como esse contexto interferiu nos comportamentos alimentares locais deles. Deve-se, porém, deixar as fontes falarem por si. E essas fontes - eles e elas falaram além do que se havia predeterminado. Pode-se e deve-se conduzir a entrevista, mas não dizer ou calar o que as fontes falam, sentem, expressam ou "não-falam", "não-sentem" e "não-expressam".

Pelo foco na alimentação, o texto também se refere aos sujeitos, pois, antes de falar de comida, estava-se falando de pessoas, com pessoas e sobre pessoas. Afinal, o que é a comida sem alguém para apreciá-la, para degustá-la, para comê-la, para prepará-la? Seria apenas um ingrediente, uma matéria sem vida, um produto sem significado. Desse modo, reforça-se que este trabalho fala de pessoas, fala de pessoas que moravam em uma Foz do Iguaçu mais antiga

\footnotetext{
1 Ver Ministério da Pesca e Aquicultura - MPA: $<$ http://www.mpa.gov.br/index.php/pesca/artesanal>.
} 
e diferente da atual, e pessoas que tiveram, de alguma forma, suas vidas marcadas pela atividade pesqueira e pela migração.

O procedimento metodológico adotado neste trabalho busca interpretar dados obtidos através de narrativas de entrevistas, sendo considerada uma pesquisa oral temática. É procedimento que pode ser visto como um método de pesquisa que busca conhecimentos sobre o passado, não sendo "[...] um fim em si mesmo, e sim um meio de conhecimento" (ALBERTI, 2005, p. 29). Neste caso, um meio de conhecimento para a investigação que se pretende realizar.

A abordagem dessa escrita, também encontra respaldo no historiador italiano Carlo Ginzburg. O autor é um dos primeiros a trabalhar com a micro-história. Abordar a microhistória é falar das beiradas, das margens, dos dados renegados, das informações quase não consideradas como tais, dando ênfase a fatos insignificantes que normalmente são ignorados dentro de um contexto geral. Método indiciário é o nome desse processo, que pode ser apreciado no livro "O queijo e os vermes". A escrita e a maneira de focar e desfocar, de seguir uma pista e esmiuçar, de escarafunchar, de esmigalhar uma massa podre, e depois modelá-la novamente, essa é uma peculiaridade de Ginzburg, é seu ponto-chave de escritor, é a microhistória dando ênfase a fatos pertinentes que normalmente são ignorados dentro de um contexto geral. O pormenorizar as informações, olhar além do óbvio, das narrativas e visualizar a simbologia por trás de cada palavra, cada gesto, cada comida, é a essência de Ginzburg que percorre o texto.

Em seu livro "Mitos, Emblemas, Sinais: morfologia e história", Ginzburg dedica o capítulo "Sinais: raízes de um paradigma indiciário", para esmiuçar os princípios do modelo indiciário. O autor inicia discorrendo sobre o "método morelliano" - do médico italiano Giovanni Morelli -, que desenvolveu um procedimento para detectar, em pinturas italianas, suas atribuições e assim identificar possíveis obras falsas, quanto testificar verdadeiros tesouros artísticos. O fato é que o método era inquietador e dizia que: “[...] é preciso não se basear, como normalmente se faz, em características mais vistosas, portanto mais facilmente imitáveis" (GINZBURG, 1989, p. 144). Morelli, portanto se prendia a detalhes como orelhas, unhas e dedos. O esforço pessoal se concentra em falar sobre as partes importantes, segundo quem pinta ou quem fala, deste modo saem os traços mais marcantes e os discursos prontos e reproduzidos. E, nas entrelinhas, o que será que pode ser visto, que minúcias essa pintura ou essa narrativa podem nos dar?

Ginzburg faz ainda uma analogia, quanto às raízes do método indiciário, ao homem caçador que "Aprendeu a farejar, registrar, interpretar e classificar pistas infinitesimais como fios de barba. [...] Gerações e gerações de caçadores enriqueceram e transmitiram esse patrimônio cognoscitivo" (GINZBURG, 1989, p.151). Seria, portanto, o paradigma venatório, relativo à caça, o início do método indiciário, tendo como ação motivadora à procura por alimento? O instinto de sobrevivência, o alimento como impulso natural para o desenvolvimento do método indiciário? O método venatório surge no instinto básico 
intrínseco de qualquer ser humano: a busca por alimento. Supõe-se o alimento como base dessa cadeia.

Ainda nessa concepção do caçador farejador e identificador de rastros e sinais, faz-se a analogia do pesquisador como um caçador, um pescador, como ser que utiliza o método venatório. Então, o seu dever é decifrar, compreender, analisar, responder ou inquietar mais sobre um determinado assunto. Se esse método indiciário pode ser desenvolvido por caçadores, médicos, pesquisadores, investigadores e pescadores, por que não incluir os comensais-intelectuais, que identificam os traços de temperos, as linhas dos ingredientes, as técnicas empregadas, decifrando cada elemento dos que compõem harmoniosamente um prato, ressaltando suas características organolépticas ${ }^{2}$, sendo estas seus aromas, sabores, saberes, texturas e apresentação visual do prato. Ou sendo aquele que identifica as notas de sabores específicos de certo vinho, com seus caracteres individuais de determinado território. O comensal utiliza seus sentidos humanos padrões, a audição, o olfato, o paladar, o tato e a visão, e entrega-se ao sexto sentido, à sua intuição.

Se orelhas, dedos e unhas diziam algo à Morelli e à Ginzburg, o quanto pirão, mandioca, massa, caboclo, italiano, "arrozfeijão", chimarrão, arroz com macaúba, pé de café e charque, têm a nos dizer? $O$ que os pescadores e suas comidas e comportamentos alimentares têm a nos dizer a mais do que já foi dito? O pormenorizar das informações, o olhar além do óbvio, além das palavras e o que elas estão falando, é tentar compreender o que elas realmente querem dizer. Olhar além da narrativa, e visualizar a simbologia por trás de cada palavra, a simbologia por trás de cada comida, este é um método indiciário.

As entrevistas com pescadores e ou familiares que vivenciaram o período da pesquisa, dispuseram da elaboração de um roteiro prévio. Porém além dessas, o trabalho contou com bibliografia sobre os temas, trazendo à mesa, desta simbólica refeição acadêmica, discussões de autores voltados às temáticas de migrações, memórias e alimentação.

Neste texto foram trabalhadas cinco entrevistas, que foram gravadas, transcritas e analisadas no decorrer desta escrita, possuindo autorização de Termo de Consentimento para a utilização dos dados. Como o objetivo desses registros não era o estudo linguístico da fala desses pescadores, optou-se pela transcrição das narrativas ajustando incorreções de português gramatical, vícios de linguagem, formas coloquiais, porém procurando manter os sentidos das falas. Durante a escrita deste trabalho, optou-se pela utilização dos nomes dos entrevistados, como estes se autodenominam, e são conhecidos nas imediações e em relações sociais. Justifica-se, portanto, a utilização do apelido. A disposição em que foram apresentados não indica o grau de importância dos mesmos, mas a ordem cronológica em que os mesmos chegaram em Foz do Iguaçu. Assim, os entrevistados foram Iracema, Coelho, Cecílio, Maria das Graças e Gabriela.

\footnotetext{
${ }^{2}$ Segundo o léxico científico-gastronômico, é a "Capacidade que um alimento possui de produzir efeitos nos sentidos (visão, olfato, tato, paladar e audição), de maneira que o percebemos, o distinguimos e o apreciamos" (ALÍCIA ELBULLITALLER, 2008, p. 175).

${ }^{3}$ Expressão que será explicada posteriormente.
} 
Manteve-se o constante cuidado/zelo em explicitar a visão de cada entrevistado e não a perspectiva dos autores sobre o tema. Eis uma metodologia já realizada anteriormente, como o que sucedeu com os documentos escritos sobre a localidade ocorridos no século XX, material analisado por Gregory (2014), que evidenciou o ponto de vista dos escritores e não a percepção das pessoas que ali moravam.

Ressalta-se que a migração não foi um tema explorado especificamente com os entrevistados. Este tema surgiu em todas as entrevistas e somente foi verificado na transcrição das mesmas. Portanto, em seguida há abordagem sobre migrações e sobre reflexões alimentares. Após este momento seguem relatos dos cinco entrevistados sobre migração, a transição para Foz do Iguaçu, e recortes de narrativas com rastros, vestígios de comida como identidade do local de origem, e/ou identidade étnica.

\section{Migração}

Os entrevistados desta pesquisa são pescadores e, além das águas, possuem outro ponto comum que é a migração. Todos os entrevistados são migrantes nas águas das Cataratas e da Usina de Itaipu, aliás, terra essa que não foi o primeiro destino migratório de nenhum deles, ou seja, dos nove entrevistados e migrantes, todos migraram de seu local de origem para outras localidades, isso até virem e se estabelecerem nos lugares em que moram na atualidade. Embora neste texto específico, estejamos trabalhando com cinco entrevistas, a pesquisa mais ampla teve mais entrevistados. Porque se mantiveram por aqui? $\mathrm{O}$ que teria acontecido para que essa terra se tornasse receptora de moradores de diversas localidades? Conforme destaca o historiador estadunidense Herbert Klein, a maioria dos migrantes não desejaria abandonar suas casas, suas terras e tudo o que remete à segurança de estar em um lugar conhecido, e que se pode chamar de "seu", seu local de origem. Ocorre, porém, como continua o autor, que, quando a sobrevivência fala mais alto, a mudança obrigatoriamente se faz presente. A migração inicia quando as pessoas têm consciência de que em seu lugar de origem não tem mais como garantir seu alimento. Essa observação mostra como uma necessidade fisiológica pode deixar as outras em segundo plano (KLEIN, 1999). Parcialmente de acordo com isso, o historiador paranaense Sérgio Odilon Nadalin diz que: "[...] ato de migrar está associado ao nosso cotidiano, à procura de algo melhor, sempre mais adiante" (NADALIN, 2001, p.9). Essa esperança acaba alimentando as migrações. Isso pode ser confirmado com a fala de Cecílio e Maria das Graças. O pescador fez a carteira em 1993 e, de lá para cá: “A gente foi migrando, então no Paraná, parou de dar peixe, nós resolvemos pescar mais para baixo, lá na Argentina. Mas lá era muito perigoso, aí abandonamos lá e subimos novamente. Aí fomos para o lago"4. Nota-se que essas mudanças ocorreram em decorrência de busca de melhores condições de pesca. Ainda se percebe a figura do Outro, do argentino

\footnotetext{
${ }^{4}$ PANSTEIN FILHO, Cecílio e PANSTEIN, Maria das Graças Ramos da Cruz. Entrevista concedida em 25/11/2014 a Paola Stefanutti, Foz do Iguaçu.
} 
como um ser perigoso. Sutilmente aparece a fronteira física delimitando e influenciando o cotidiano e a atividade pesqueira. Conforme Maria das Graças nos diz: "Procurando melhoria, procurando mais peixe. Também pescamos no Rio Iguaçu"5 - relembra a pescadora. Retomase a discussão com Nadalin (2001), que associa a migração à procura de algo melhor.

E oposta à visão unilateral de Klein, Nadalin relata uma série de outras razões que levam ao fenômeno migratório, como a posse, a terra, melhores condições de vida, a aventura, o conhecimento, o novo, a conquista, o pioneirismo (presente nas falas de alguns pescadores) e por outros motivos. Há, portanto, migração, não apenas quando se tem um contexto de necessidade de mudança, mas quando há uma motivação pessoal ou coletiva para tal. Ainda, segundo o autor, as migrações são fenômenos sociais de natureza histórica, e que: "[...] cada migração adquire uma especificidade única e original" (NADALIN, 2001, p.10). Completando essa perspectiva, Gregory (2011) acrescenta que o ato migratório ocorre de um lugar a outro, porém os lugares são processos e não são estáticos. Lugares têm significados, lugares têm sentimentos, lugares têm pessoas, lugares têm vida, lugares têm memórias.

Dentre as necessidades de pertencimento, aconchego e segurança estão aspectos ligados à terra, como geografia, relevo, tipo de solo, clima, altitude, pecuária, agricultura, disponibilidade de alimento; e aspectos sociais e culturais, como histórias, lendas, folclore, costumes, tradições, danças, músicas e comportamentos alimentares. Essas particularidades formam a identidade de um determinado grupo humano. Parte-se do pressuposto de que a identidade cultural de um grupo social está essencialmente vinculada à sua memória, às suas lembranças ou, conforme menciona Ernest Renan (1997), filósofo e historiador francês, em seu texto que trata dos aspectos da formação do Estado-nação, além da memória, também há o esquecimento proposital, sendo que, para a formação de uma sociedade, é vantajoso saber esquecer - esquecer as diferenças e realçar as razões que fazem o grupo estar em unidade. Esse é um fator condicionante da relação indivíduo-sociedade, pois é através dela que o indivíduo se adapta e se reconhece em um ambiente como sendo seu. E na questão migratória também há esse processo do saber esquecer, e saber se adaptar às realidades disponíveis no novo território.

Quem pode contribuir com essa temática é a psicóloga e professora da USP Ecléa Bosi. Em seu livro "Memória e Sociedade: lembranças de velhos", a autora discute sobre a velhice e as memórias tendo como pano de fundo reflexões sobre narrativas de oito idosos com mais de setenta anos de idade cada um e que têm algo em comum: a vivência na cidade de São Paulo. Na formação da identidade de um grupo social, a memória social tem um papel fundamental, pois o passado compartilhado por seus membros influencia a imagem que o grupo tem dele mesmo no presente. Nesse contexto, Bosi (1994, p.408-411) diz que: "Uma memória coletiva se desenvolve a partir de laços de convivência familiares, escolares, profissionais. Ela entretém a memória de seus membros, que acrescenta, unifica, diferencia, corrige e passa a limpo".

\footnotetext{
${ }^{5}$ PANSTEIN FILHO, Cecílio e PANSTEIN, Maria das Graças Ramos da Cruz. Entrevista concedida em 25/11/2014 a Paola Stefanutti, Foz do Iguaçu.
} 
Diversos pontos de referência inserem a memória individual na coletiva, o que envolve um processo de seleção e negociação para que haja o máximo de pontos de contato construídos sobre uma base comum, fundamentando e reforçando o sentimento de pertencimento e as fronteiras socioculturais, gerando coesão pela adesão afetiva e não pela coerção. São esses os elementos que, uma vez codificados como símbolos, servem como construção de uma referência cultural. Mesmo assim, porém, Bosi (1994, p.411) afirma que: "Por muito que deva à memória coletiva, é o indivíduo que recorda. Ele é o memorizador e das camadas do passado a que tem acesso pode reter objetos que são, para ele, e só para ele, significativos dentro de um tesouro comum”. Assim, a memória coletiva depende e negocia com o indivíduo narrador, que escolhe o que contar, como contar e porque contar.

Dentre esses pontos de referência, pode-se mencionar e relacionar os comportamentos alimentares. Na sequência, há uma série de relatos de migrantes que demonstram, de algum modo, a relação entre a migração, seu lugar de origem, sua identidade e a comida. Primeiramente trata-se de esclarecer a escolha do termo comportamentos alimentares e refletir sobre comida e alimento.

\section{Reflexões Alimentares}

Justifica-se, neste momento, a expressão "comportamentos alimentares". A antropóloga espanhola Sílvia Carrasco i Pons, especialista em antropologia da alimentação, faz uma rica e densa explanação sobre o cuidado com o uso das expressões referentes à alimentação. Segundo a antropóloga, o termo "hábitos alimentares" tem um enfoque biomédico e nutricional, sendo utilizado na área da saúde. Já autores anglo-saxões e franceses, de formação em história e antropologia, utilizam expressões como estilos alimentares, práticas alimentares, experiências alimentares, comportamento alimentar, buscando um termo que "[...] se ajusta melhor à realidade sociocultural mais ampla da alimentação" (PONS, 2005, p.109). A autora completa:

[...] o antropólogo que estuda a alimentação considera sempre o ser humano em uma escala social, não decompõe os alimentos em substâncias nutritivas, mas em propriedades de uma ordem social e material atribuídas por um determinado grupo humano. Interessa-se, como vimos, pelas seleções culturais entre os recursos do meio e as técnicas disponíveis e pelas categorias de indivíduos que discriminam em relação aos processos alimentares. (PONS, 2005, p.109-110).

Pode-se estabelecer um diálogo com a nutricionista Rosa Wanda Diez Garcia, que, apesar de ser da área da saúde, desenvolve trabalho sobre as representações e práticas da alimentação no contexto urbano e defende o uso do termo "comportamento alimentar", definindo-o como: 
Entendemos por comportamento alimentar não apenas as práticas observadas empiricamente (o que comemos, quanto, como, quando, na companhia de quem e onde), mas também os aspectos subjetivos que envolvem a alimentação: os socioculturais e os psicológicos (alimentos e preparações apropriados para situações diversas; escolhas alimentares; comida desejada e apreciada; alimentos e preparações que gostaríamos de apreciar; a quantidade de comida que pensamos que comemos etc.) [...] [contempla-se] os aspectos subjetivos do comportamento alimentar, por entendermos que estes balizam as práticas alimentares. (GARCIA, 2005, p.214).

A autora ainda ressalta, mais adiante, que nas práticas alimentares estão incluídas: "[...] a identidade cultural, a condição social, a memória familiar expressa nos procedimentos relacionados à escolha e à preparação do alimento e ao seu consumo propriamente dito" (GARCIA, 2005, p.277).

Um aspecto alimentar que pode ser pormenorizado, está na fala do historiador e antropólogo, que se deleita no tema, Roberto DaMatta, que trata da distinção entre comida e alimento. $\mathrm{O}$ autor diz que: "Temos então alimento e temos comida. Comida não é apenas uma substância alimentar, mas é também um modo, um estilo e um jeito de alimentar-se. E o jeito de comer define não só aquilo que é ingerido como também aquele que ingere" (DAMATTA, 1986, p.55-56, grifo nosso). O alimento então se torna a peça bruta, e a comida seu refinamento. O selvagem e o doméstico, o natural e o cultural, o cru e o cozido, o alimento e a comida. Lembra-se aqui da concepção do cru e do cozido do antropólogo francês Lévi-Strauss.

Nesse sentido, pode-se refletir que nem tudo o que alimenta é bom ou socialmente aceitável. Do mesmo modo, nem tudo o que é alimento é comida. Para essa discussão, não poderia faltar outro antropólogo francês dedicado ao estudo da alimentação, que é Claude Fischler, ao dizer, sucintamente, que: "[...] tudo o que é biologicamente comestível não é culturalmente comestível” (FISCHLER, 1995, p.33, tradução nossa). Ou seja, nem tudo o que é biologicamente comestível, o é culturalmente. É a diferença entre o alimento e a comida. A carne bovina pode ser comida, comestível na cultura gaúcha, mas não o é na cultura indiana, por uma questão religiosa. Assim como alguns insetos são comida, comestíveis em alguns países asiáticos, ou tribos indígenas brasileiras, mas não o são em outras culturas. Mesmo assim, porém, tanto a carne bovina como os insetos continuam sendo alimento.

$\mathrm{O}$ alimento constitui o ato de alimentar-se, nutrir-se. Enquanto comida envolve todo o contexto sociocultural à mesa, o que comer, quando comer, onde comer, porque comer, o jeito de comer, o modo de preparo, os acompanhamentos, os acompanhantes, o tempo e toda a ritualização à mesa. Os comensais comem cultura. Conscientes ou não deste processo, comer não é um ato neutro, assim como a comida não o é, pois a escolha dos comensais vem carregada de significados e de simbologias culturais. Então, cabe dizer que a comida é culturalizada, afinal comemos comida, comemos cultura, comemos momentos, comemos pessoas. 
O cozinhar tem uma relação singular entre comida e indivíduo, e as memórias que decorrem dessa prática são as evidências disso. As memórias afetivas, a comida como uma lembrança e a consequente valorização das produções caseiras. $\mathrm{O}$ comensal come o carinho, come a dedicação, come o sentimento, come o ritual. Pode-se estabelecer uma conexão com a fala da historiadora paranaense Mariana Corção (2006, p.8):

A memória gustativa é uma das formas de memória que representam, no nível individual, o valor da permanência de vestígios passados. O indivíduo atribui importância àquele elemento pelo o que aquilo representa para ele próprio, não há necessidade de construir um discurso para legitimar sua significância social.

Fazer gastronomia, mais do que fazer comida, é pensar comida, e refletir sobre as relações sociais envolvidas, os seres envolvidos: quem faz e quem come; o que faz e porque faz; como prepara e porque prepara. Pensar em comida é realizar esse momento de ruminar, da compreensão do contexto de como essa comida é escolhida, valorizada, elaborada, digerida, apreciada ou apenas engolida. Assim, continua-se, neste nosso texto, este processo de reflexões sobre comida e não sobre alimento.

A seguir são apresentados os relatos de migrações e comportamentos e de práticas alimentares dos cinco pescadores e seus desdobramentos, cooperando em uma visão holística para o tema da migração e da alimentação. Demonstrando de algum modo, a relação entre a migração, seu lugar de origem, sua identidade étnica e seus vestígios alimentares.

\section{Os Migrantes e seus Rastros de Comida}

Iracema Berlanda de Andrade, viúva do pescador Aristeu Matos de Andrade, é gaúcha de Veranópolis. Hoje com setenta anos, veio do Rio Grande do Sul com dez anos com destino a Matelândia, onde morou até os dezesseis anos. Sua história particular se funde com a de outras famílias que migraram para essa área:

Matelândia, naquele tempo estava sendo colonizada, quando mudamos, acho que tinha umas dez, quinze famílias. Era pequeno, mas nós fomos, meu pai era corretor de terra, ele iá lá no Rio Grande e trazia uma caminhonete cheia de gente, para comprar terra em Matelândia, ele trabalhava na Pinho e Terras naquele tempo, era corretor de terra. Ele trouxe muita gente do Rio Grande. ${ }^{6}$

Apesar de ter falecido há dezessete anos, as histórias de Aristeu permanecem:

Meu marido era de Anita Garibaldi, perto de Lajes, em Santa Catarina, ele e a família vieram também para o Paraná. Naquele tempo a fama estava para o

\footnotetext{
${ }^{6}$ ANDRADE, Iracema Berlanda de. Entrevista concedida em 1\%/12/2014 a Paola Stefanutti, Foz do Iguaçu.
} 
Paraná, aí vieram, compraram terra ali, nós também tínhamos terra, nós morávamos na vila, e éramos vizinhos. Aí minha irmã começou a namorar com um, eu comecei a namorar o outro, e a outra começou a namorar com o outro, três casaram, três irmãs com três irmãos [ela abriu um sorriso leve, gostoso]. ${ }^{7}$

Nesta fala constata-se um costume da união entre famílias próximas, formando estruturas sociais baseadas no matrimônio entre elas, fortalecendo as relações de poder entre grupos próximos. Outro costume da época pode ser notado quando Iracema conta que: "Aí casei já velha, com dezesseis anos" ${ }^{\prime 8}$. E chegaram casados a Foz do Iguaçu um ano depois, em 1961, quando Iracema tinha dezessete anos. E, desde então, moravam às margens do Rio Paraná, até saírem de lá, por conta da desapropriação da Itaipu, em 1979. Todavia, uma frase da entrevistada pode ser destacada:

Aí nós moramos lá dentro onde é a Itaipu, nós morávamos lá. Nós morávamos pertinho do Rio Paraná, em cima praticamente do Rio Paraná, daí não sei se você conheceu o Alvorada, Vista Alegre, ouviu falar? Nós morávamos em Vista Alegre, então os fundadores da Vista Alegre foi a nossa família. ${ }^{9}$

Essa frase de efeito com relação ao pioneirismo no povoado pela família merece destaque. Parece que ela tem maior influência e poder. $\mathrm{O}$ discurso do pioneirismo continua sendo reproduzido pelas gerações da família. Representando que eles possuem um direito maior perante os demais, por terem chegado primeiro e serem os pioneiros do local. Uma bibliografia que aborda sobre a vila Alvorada do Iguaçu é a dissertação de Kleber Dreicy Melchior, que, além de tratar das conturbadas desapropriações, refere-se especificamente às memórias acerca do deslocamento dos mortos, da remoção do cemitério da vila em virtude da inundação que haveria de vir com a formação do Lago de Itaipu em 1982. Essa dissertação discute, assim, a ligação do homem e do território (MELCHIOR, 2012). Além dessa discussão, o autor caracteriza a localidade, sendo constituída majoritariamente por migrantes dos estados do Rio Grande do Sul e de Santa Catarina, exatamente como o casal Iracema e Aristeu.

Nas narrativas sobre suas memórias alimentares, foram realizados alguns recortes que possuíam indícios de comida como identidade do local de origem e/ou identidade étnica, tais como segue. Iracema recorda-se que: "Como ele [Aristeu, o esposo], era de Santa Catarina, ele gostava de fazer pirão. Lá em Santa Catarina eles comem muito pirão, e eu não gostava do tal do pirão, agora eu gosto, por azar, né. Eu gosto de pirão" ${ }^{10}$. Percebe-se uma modificação

\footnotetext{
${ }^{7}$ ANDRADE, Iracema Berlanda de. Entrevista concedida em 1\%12/2014 a Paola Stefanutti, Foz do Iguaçu.

${ }^{8}$ ANDRADE, Iracema Berlanda de. Entrevista concedida em 1\%/12/2014 a Paola Stefanutti, Foz do Iguaçu.

${ }^{9}$ ANDRADE, Iracema Berlanda de. Entrevista concedida em 1\%/12/2014 a Paola Stefanutti, Foz do Iguaçu.

${ }^{10}$ ANDRADE, Iracema Berlanda de. Entrevista concedida em 1\%12/2014 a Paola Stefanutti, Foz do
} 
nos comportamentos alimentares por uma questão de convivência e aproximação com determinadas práticas alimentares - desta vez, da mulher para com os comportamentos alimentares do marido.

Pode-se fazer uma pormenorização da comida mencionada, o pirão. O consagrado autor da história da alimentação no país, Luís da Câmara Cascudo, no livro "História da Alimentação no Brasill”, descreve sobre este prato:

Pirão é sinônimo da própria alimentação brasileira. Dá subsistência total. O adagiário é convincente. [...] Conduto essencial no cardápio nacional, além da farofa, é suficiente pouco mais para que constitua refeição. "Por cima do pirão basta um engano". "Pirão é que enche barriga". Faz bucha. Facilita e provoca a peristalse. [...] Técnica portuguesa com material brasileiro, o pirão é uma obra-prima nacional, colaboração afetuosa e positiva na permanência realizadora como a mulata. (CASCUDO, 2004, p.103-106)

Além da singular descrição do pirão, Cascudo agrega e agracia sobre a comida pesada, comida forte, que dá sustância. Outro ingrediente que aparece nas narrativas de Iracema foi a mandioca. Segundo a entrevistada:

Mandioca naquele tempo não tinha comércio em Foz. Ninguém falava em mandioca. Nós mesmos nunca comíamos mandioca naquele tempo. A gente não sabia, não era um prato de Santa Catarina, nem do Rio Grande. Então, a gente acostumou depois com os paraguaios, sei lá, foi indo, né. Hoje a gente não come sem mandioca, né? [rindo]. ${ }^{11}$

O contato com outra cultura alimentar pode modificar o comportamento alimentar de um indivíduo. Nesse caso, a alteração foi tamanha, ao ponto de ela declarar que não comia o produto e hoje que não come sem ele. Nota-se que ela se remeteu às suas raízes e às de seu esposo, em busca de explicação para o não consumo do alimento. Afinal, a mandioca, uma raiz comestível, era um produto sem raízes sociológicas e culturais para eles, já que o produto, segundo Iracema, não era de Santa Catarina, nem do Rio Grande do Sul. Mas será que não era? Para essa gaúcha que veio de Veranópolis, segundo suas memórias ou as memórias que ela negociou em narrar, o produto não era consumido em seu local de origem, o que não significa que nos dois estados brasileiros descritos o produto não viesse sendo consumido.

A mandioca é alimento indígena, legado para as gerações que ocupam o território nacional. O brasileiro come mandioca, mas o brasileiro, nesta fronteira, vê nesse alimento, o Outro, o paraguaio, assim não reconhecendo esse alimento como sua comida e, quando o reconhece, assume que é por causa da fronteira que o alimento é consumido, com influência paraguaia. Seja pelo Paraguai ou pelo Brasil, a mandioca está enraizada nesta entrevistada.

Iguaçu.

${ }^{11}$ ANDRADE, Iracema Berlanda de. Entrevista concedida em 1\%/12/2014 a Paola Stefanutti, Foz do Iguaçu. 
Estabelece-se uma relação da comida como identidade. Relembrando os comportamentos alimentares, Iracema ainda diz que: "Nossa comida era mais polenta, era arroz, feijão. Eu sou de origem italiana, ele [Aristeu, o esposo] não, ele era caboclo ${ }^{12}$. Então, ele era arroz, feijão e carne, carne de porco e banha, tudo que era troço assim. E eu já era mais de massa, de italiano, né?"13. Nota-se que, na frase de Iracema, seu esposo se torna a própria comida, afinal "ele era arroz, feijão e carne [...]”. Esse momento foi único, pois quando ela se referia à comida do caboclo, a voz engrossava, franzia a testa. E falava como se estivesse dando uma ordem à comida, com o maior esforço para aparentar brutalidade e grosseria, como se aquela comida representasse isso para si mesma. Diferentemente, quando narrava sobre a massa, ela parecia uma manteiga derretendo em uma frigideira quente, uma massa ao molho escorrendo pelo garfo. A cena foi única e a voz, nós a temos gravada...a comida bruta e a comida delicada e fina, a voz rude e a voz suave e leve, como uma massa italiana.

Esse reforço da identidade em ser italiana, através da massa, pode ser uma das razões para a negação/negociação do não consumo da mandioca, mencionada anteriormente, como se essa comida não a representasse. Supõe-se que, nesta e em narrativas seguintes, Iracema esteja mais preocupada em demarcar fronteiras e reforçar identidades (italianas) do que em relatar o cotidiano à mesa. Nessa questão dialoga-se com Leonir Colombo (2015, p.191), que trata sobre memórias na região, que diz: “[...] as memórias são seletivas e pragmáticas, ou seja, possuem objetivos". Esse processo de negociação das memórias do que deve ser esquecido e do que deve ser reforçado por ser conveniente é sutil, porém presente nas narrativas.

Cascudo, na já referida obra "História da Alimentação no Brasil", dedicou um subcapítulo sobre a influência de alemães e de italianos na cozinha brasileira. Sobre estes últimos, o autor destaca a importância da massa:

Trouxeram para a culinária nacional o gosto das massas de farinha de trigo, com os molhos espessos e condimentadores, resistindo às seduções da pimenta, e teimando no azeite doce e banha de porco contra o dendê e o leite de coco. [...] Ninguém modificou o acepipe italiano, que se infiltrou pela população de todas as paragens, em todas as classes, em todas as economias aquisitivas. Apenas a massa, a pasta italiana, pastasciutta, constituindo uma iguaria no Brasil, é um conduto. Na Itália, o macarrão é uma refeição. No Brasil, concorre com a farofa, arroz, feijão, acompanhando carne ou peixe. É um colaborador saboroso, mas não é um elemento autônomo e suficiente [...] (CASCUDO, 2004, p.620, grifo do autor).

Sobre o arroz e o feijão, pode-se fazer um diálogo com DaMatta, em seu livro "O que faz o brasil, Brasil?". Ele traz a concepção de que a formação da identidade de um indivíduo se dá juntamente com a construção de sua sociedade, através da prática de seus costumes, hábitos e regularidades, tornando os indivíduos singulares. $\mathrm{O}$ autor faz uma explanação de

12 A identidade cabocla é complexa, e não cabe discussão sobre o conceito neste momento.

${ }^{13}$ ANDRADE, Iracema Berlanda de. Entrevista concedida em 1\%/12/2014 a Paola Stefanutti, Foz do Iguaçu. 
temas que caracterizam a sociedade brasileira, como a religião, carnaval, festas, espaço casa versus rua, mulheres e comida. Explanando a parte da alimentação, ele diz que:

Mas qual é a comida brasileira básica? Certamente que se trata do feijão com arroz, essa comida que é até mesmo usada como metáfora para a rotina do mundo diário. [...] De tal modo que o feijão, que é preto, deixa de ser preto, e o arroz, que é branco, deixa também de ser branco. (DAMATTA, 1986, p. 56).

Pode-se dizer então que o arroz e o feijão misturados formam um novo elemento, o "arrozfeijão", 14 tornando-se uma única comida, um ser híbrido. E quem o consome se torna a própria comida ao misturar os ingredientes. Algo antropofágico, algo simbólico, algo cultural, algo brasileiro.

Antônio de Souza, o Coelho, foi um pescador à parte. Foi “à parte”, primeiramente, pela negação em ser pescador. Ele logo disse: "Eu não sou pescador" ". Isso ele repetiu constantemente durante a entrevista, um não-ser, uma identidade negada a si mesmo, mas não aos demais à sua volta, que o reconhecem como tal: "Sou pai de pescador"16. O não-pescador hoje, com setenta e dois anos, veio para Foz do Iguaçu para trabalhar no canteiro de obras da Itaipu em 1978 e se estabeleceu. Era perceptível uma resistência em falar de suas raízes, de onde veio, mas, por fim, como quase quem conta um segredo, confessou que é natural de Avanhandava, interior de São Paulo, porém veio para Londrina com quatro anos de idade e pelo Paraná permaneceu. Coelho possuía uma forte memória com datas, pois ele mencionou cada ano, o ano em que foi "fichado na Itaipu" 17 , o ano em que se mudou para Londrina e outras cinco cidades em que morou antes de Foz do Iguaçu, relatando até sobre o período da ditadura com seus respectivos presidentes, mas não que estivesse disposto a falar sobre isso, como de fato não estava - mas essa é outra questão.

É proibido plantação perto do rio, pela questão de preservação ambiental e mata nativa, porém quando questionado se havia alguma plantação, Coelho diz: "Não, não, aí tem um pé de abóbora que nasceu, umas batatas que já tinha ali, e eu aproveitei e plantei o quê? Três pés de café, que é a minha paixão ver eles crescerem. Venha aqui para você ver" "18. A fala do não-pescador é até engraçada de ouvir/ler, e ele falou sério, como se um pé de abóbora surgisse do nada, do mesmo modo que as batatas. Essa inocência na fala, para reforçar sua própria inocência, chama a atenção. Ao chegar atrás da casa, ele continuou:

Esse, esse, e aquele lá, [apontando para os três pés de café plantados separadamente] só de ver eles crescerem, eu me lembro, quando nós morávamos na roça, um pé de café crescia um palmo por dia, por causa dos

\footnotetext{
${ }^{14}$ Neologismo criado pela co-autora Paola Stefanutti, simbolizando uma comida brasileira híbrida e recordando a pronúncia popular.

${ }^{15}$ SOUZA, Antônio de. Entrevista concedida em 22/12/2014 a Paola Stefanutti, Foz do Iguaçu.

${ }^{16}$ SOUZA, Antônio de. Entrevista concedida em 22/12/2014 a Paola Stefanutti, Foz do Iguaçu.

${ }^{17}$ SOUZA, Antônio de. Entrevista concedida em 22/12/2014 a Paola Stefanutti, Foz do Iguaçu.

${ }^{18}$ SOUZA, Antônio de. Entrevista concedida em 22/12/2014 a Paola Stefanutti, Foz do Iguaçu.
} 
tocos, dos paus podres, hoje se não adubar não sai nada, você sabe. É a minha paixão, só para matar saudades. Tá aqui pertinho, aí eu jogo água da roupa, aqui eu lavo minha roupinha, jogo a água do tanque aí, e ele tá bonito. Mas nem devia, porque não é pra plantar. Eu plantei só por isso aí mesmo. E eu joguei semente de abóbora aí e pegou [com um tom de voz dizendo, não foi culpa minha, eu só joguei, e pegou, fazer o que agora, né? ${ }^{19}$

Além dos discursos e das narrativas, a memória também perpassa e pode ser contemplada pelos objetos materiais. "A memória é assim guardada e solidificada nas pedras [...]" (POLLAK, 1989, p. 10). Quando nos deparamos com esses pontos de referência de uma época distante, usualmente integra-se em próprios sentimentos de pertencimento, de filiação, de origem. Neste ponto se pode estabelecer um diálogo com Valdir Gregory, em seu livro intitulado "Os Eurobrasileiros e o Espaço Colonial", em que aborda, no quarto capítulo, a questão da fronteira e o espaço colonial em crise, sendo crise a tentativa de reconstruir o velho e construir o novo. $\mathrm{O}$ autor faz um levantamento sobre o cotidiano e a memória colonial na fronteira, tratando a questão da mudança/transição do colono, de uma colônia antiga para a nova. E traz a concepção da escolha dos objetos, coisas, materiais. O que irá ficar, ser vendido ou deixado para trás, e o que será levado na viagem, rumo à nova terra e nova vida. Diante dessa situação, ele afirma que:

Pode-se supor que o fato desses bens serem mantidos na posse familiar trazia segurança de que, no novo, o velho se manteria. Lidar com os mesmos objetos com que se lidava na terra natal significava segurança e garantia de que a mudança não implicava em perda. (GREGORY, 2002, p. 177).

O ponto em questão não era a perda de bens, mas a perda do sentido de família, da perda de identidade e do sentimento do local de origem. Tedesco $(2013$, p. 344) diz que: "Os sentimentos de memória podem ser muito profundos e intensos; desse modo, quanto mais significativos, mais difíceis de serem apagados e não lembrados". Assim, com a frase "É a minha paixão, só para matar saudades" 20 , os três pés de café de Coelho plantados ali, atrás da casa do não-pescador, é a simbologia do rememorar, de voltar a viver através, neste caso, de uma planta, os períodos anteriores, sem que se percam na memória. O pai de Coelho sempre havia trabalhado em lavouras de café. Possuir aqueles três pés era algo representativo, era trazer a sensação da segurança de estar em "casa".

Os próximos entrevistados foram o casal de pescadores, Cecílio Panstein Filho e Maria das Graças Ramos da Cruz Panstein. Cecílio informou estar com cinquenta e cinco anos de idade, enquanto Maria das Graças, com cinquenta e seis. Eles chegaram casados em Foz do Iguaçu em 1989 e já pescavam. Porém, ele só fez a carteirinha profissional alguns anos após, em 1993:

Quando nós viemos pra cá, eu tinha uma chácara em Santa Helena. E lá nós morávamos na beira do lago. E lá eu mexia com pescaria. Mas lá era

\footnotetext{
${ }^{19}$ SOUZA, Antônio de. Entrevista concedida em 22/12/2014 a Paola Stefanutti, Foz do Iguaçu.

${ }^{20}$ SOUZA, Antônio de. Entrevista concedida em 22/12/2014 a Paola Stefanutti, Foz do Iguaçu.
} 
informal. Tinha uma rampa de acesso lá. Mas aí, eles [possivelmente polícia] fecharam a rampa por conta do contrabando. Então eu me mudei para Foz do Iguaçu. E por questão de gostar e sempre estar na beira do rio, me associei na colônia de pescadores, como pescador profissional. $\mathrm{Na}$ intenção assim, eu vou ser pescador profissional, mas para ter um documento como pescador profissional. Porque eu sempre estava na beira do rio pescando. E tinha medo de uma hora chegar uma fiscalização e me [pausa] empacar com alguma coisa, impedir. ${ }^{21}$

Neste relato, verifica-se que o contrabando e o consequente fechamento da rampa de acesso ao Lago de Itaipu, foi a causa da migração da família. A rampa era acesso de pescadores e de contrabandistas. O contrabando pode também alterar o fluxo das pessoas. Além dessa mudança, o casal relatou outras, em virtude de melhoria de pescaria e de vida, conforme relatos em páginas anteriores.

Durante as narrativas, o pescador mostrou algumas fotos. Em uma das fotos aparece o casal, e Cecílio está com a cuia de chimarrão. Ele disse que sua mãe é gaúcha, descendente de alemão, e o pai é catarinense e descendente de húngaro. Salientou que o hábito do chimarrão não veio da família.

Quando nós mudamos para Santa Helena, na comunidade de Vila Celeste, tinha quatro pés de ervas muito bonito. Gente do céu, os caras fazem um chimarrão usando essas ervas aqui e esse troço. Aí cortei aqueles galhos, pedi umas informações para uma gauchada lá. Faz assim, assim, assado. Fui fazendo, fui quebrando a cara. De repente, eu peguei o jeito, começamos a fazer uma erva colossal, uma erva cinco estrelas. Nós mesmos fazíamos. Eu carejava, socava ela no pilão, então a gente aprendeu a tomar chimarrão ali em Santa Helena, fazendo. ${ }^{22}$

Com a expressão "Eu peguei o jeito", Cecílio não se refere apenas à prática, mas o transpassar cultural e saberes tradicionais. Pode-se levantar a hipótese de que, adquirindo aquele hábito, eles estariam mais próximos, e de certa forma pertencendo àquela comunidade "gauchada".

Maria das Graças lembra, remetendo à memória gustativa dos filhos, e não dela própria: "E ele [filho caçula] não esquece de um arroz que esse daí fazia [apontando para o Cecílio], que era o que mais ficava acampado na barranca lá com ele, era arroz com macaúba"23.

Nesse momento o olhar de Cecílio se perdeu, encontrando conforto no chão, onde parecia refletir a imagem dos dois compartilhando esse momento. Foi a única vez, durante as

\footnotetext{
${ }^{21}$ PANSTEIN FILHO, Cecílio e PANSTEIN, Maria das Graças Ramos da Cruz. Entrevista concedida em 25/11/2014 a Paola Stefanutti, Foz do Iguaçu.

22 PANSTEIN FILHO, Cecílio e PANSTEIN, Maria das Graças Ramos da Cruz. Entrevista concedida em 25/11/2014 a Paola Stefanutti, Foz do Iguaçu.

${ }^{23}$ PANSTEIN FILHO, Cecílio e PANSTEIN, Maria das Graças Ramos da Cruz. Entrevista concedida em 25/11/2014 a Paola Stefanutti, Foz do Iguaçu.
} 
duas entrevistas realizadas na sala da casa do pescador, que Cecílio desviou o olhar, eis que não tinha o domínio emocional da situação. Estava perdido em seus pensamentos e tinha sido levado, por alguns instantes, para outro local, um não-lugar. Fez questão de explicar:

Macaúba é um coqueiro assim, que tem bastante espinho. O nome é coco macaúba mesmo. Ele é um coqueiro tudo cheio de espinho, o tronco dele, as folhas tudo tem espinho. Então ele dá o cacho igual ao coqueiro, só que invés de ser coqueiro miudinho, ele é bem grandão. E ele tem um coquinho por dentro, e por fora ele tem uma massa bem firme assim. Só que ela tem um sabor diferente ${ }^{24}{ }^{25}$

Após explicar sobre o ingrediente, Cecílio conta que, quando morou no Mato Grosso, tomou conhecimento que os índios faziam macaúba com peixe, inserindo assim o fruto na alimentação da família. Utilizando apenas a parte interna, carnuda, a polpa do fruto, ele conta que fritava na gordura, refogava o arroz, cozinhando o arroz naquele refogado. Depois sua esposa complementa: “[...] pegava um monte daquele lambarizinho pequenininho, fritava bem fritinho. E fazia só aquele arroz. Arroz com macaúba. Ele não esquece até hoje. Meu Deus!" 26. Mesmo depois desse deleite de memórias gastronômicas, Cecílio reforça que a macaúba é como jiló e quiabo "[...] tem que ser quem gosta“"27. Observa-se como a transmissão de conhecimentos rotineiros ocorre naturalmente no cotidiano. Sabedoria de indígenas do Mato Grosso, que utilizavam o fruto, a transmissão de conhecimento, possivelmente de terceiros, a posse do conhecimento e a transformação dentro da realidade vivida pelo pescador, que replica, tempos mais tarde, a receita, como sendo ele detentor daquele conhecimento. Há uma relação dúbia entre tradição e inovação, tal como comenta Luce Giard, historiadora francesa que juntamente com Michel de Certeau escreveu "A invenção do cotidiano: 2. Morar, cozinhar":

[...] é por causa de seu papel central [alimentação] na vida cotidiana da maioria das pessoas, independente de sua situação social e de sua relação com a "cultura erudita" ou com a indústria cultural de massa. Além disso os hábitos alimentares constituem um domínio em que a tradição e a inovação têm a mesma importância, em que o presente e o passado se entrelaçam para satisfazer a necessidade do momento, trazer a alegria de um instante e convir às circunstâncias. (GIARD, 2008, p. 212, grifo da autora).

${ }^{24}$ Os frutos são consumidos in natura nas zonas rurais do interior do país, podendo ser utilizados para uso culinário. Ver: KINUPP, Valdely Ferreira; LORENZI, Harri. Plantas alimentícias não convencionais (PANC) no Brasil: guia de identificação, aspectos nutricionais e receitas ilustradas. São Paulo: Instituto Plantarum de Estudos da Flora, 2014.

${ }^{25}$ PANSTEIN FILHO, Cecílio e PANSTEIN, Maria das Graças Ramos da Cruz. Entrevista concedida em 25/11/2014 a Paola Stefanutti, Foz do Iguaçu.

${ }^{26}$ PANSTEIN FILHO, Cecílio e PANSTEIN, Maria das Graças Ramos da Cruz. Entrevista concedida em 25/11/2014 a Paola Stefanutti, Foz do Iguaçu.

${ }^{27}$ PANSTEIN FILHO, Cecílio e PANSTEIN, Maria das Graças Ramos da Cruz. Entrevista concedida em 25/11/2014 a Paola Stefanutti, Foz do Iguaçu. 
Outra pescadora que pode contribuir com essa discussão é Gabriela Cichorsti. Natural de Rio Negro, no estado do Paraná, chegou a Foz do Iguaçu em 1991, porém ela e seu esposo Paulo pescavam em Guaíra, com os dois filhos, antes da inundação das Sete Quedas. E em Altônia: "Foi onde o Márcio ficou doente, deu um tumor no cérebro, e perdeu a visão [essa parte, teve uma pausa, as palavras foram faladas espaçadamente]. E dali daquele tempo, a gente foi para Rio Negro, ficamos lá, e de lá, em 91, viemos para cá [Foz do Iguaçu]"28.

Nos recortes realizados nas narrativas de Gabriela, levantou-se alguns rastros de comida de terceiros. Ela relata que, em 1982, quando moravam em Altônia, eles faziam charque e peixe defumado, pois iam pescar nas ilhas.

Daí lá leva sal, leva caixa, leva tudo. Aí lá vai pegando, limpando e salgando dentro das caixas. Defumado, defumado também. Tinha lenha, né? [Depois que vieram para Foz] Nunca mais fizemos. Um dia eu quero fazer. Porque o peixe de $\operatorname{couro}^{29}$ não dá charque, ele derrete, ele cai, ele derrete tudo. ${ }^{30}$

Gabriela complementa: "A viabilidade do comércio é o charque de peixe. Você leva uma caixa com charque de peixe lá, vende tudo"31. Sobre essa questão, Márcio o filho cego, que acompanhava a entrevista, acrescentou:

[...] o povo tem a tradição de comer esse negócio. É comércio lá da região. E aqui não tem esse negócio. Porque lá, até hoje, se você levar um peixe fresco, para vender pra eles, eles não aceitam. Tem que ser no charque. É uma tradição, sabe? E era não, é gostoso o charque do peixe. Tem que vê, quando está bem charqueado, se come ele cru assim, bem sequinho. ${ }^{32}$

Apesar de a narrativa não ser sobre Foz do Iguaçu, é enriquecedor o comparativo com Altônia, onde também corre o Rio Paraná, que demonstra como a infraestrutura local, com falta de energia elétrica, desencadeou um método de conservação, que, por sua vez, influenciou e influencia os comportamentos alimentares e dita a relação comercial do pescado entre pescadores, comerciantes e consumidores finais. Permanecendo os hábitos até hoje, seria um exemplo de adaptação paliativa que se tornou permanente. Gabriela continua ainda sobre o charqueado: "E o charqueado chega a ficar um ano na caixa. Porque eles usam folha de bananeira não verde. Põe uma camada, põe folha de bananeira seca, e põe outra camada e vai indo. Daí tem gente lá em cima [Altônia] que se prepara para esse período de piracema para não ficar sem peixe"33. Assim garantem a disponibilidade do produto mesmo em períodos sem tê-lo fresco. As especialistas da área, Nunes e Pedro (2011), no capítulo "Salga

\footnotetext{
${ }^{28}$ CICHORSTI, Gabriela. Entrevista concedida em 12/12/2014 a Paola Stefanutti, Foz do Iguaçu.

${ }^{29}$ O peixe de couro possui uma carne mais gordurosa, e acaba se soltando, diferente do peixe de escama, que possui uma carne mais magra e consegue manter a estrutura.

${ }^{30}$ CICHORSTI, Gabriela. Entrevista concedida em 12/12/2014 a Paola Stefanutti, Foz do Iguaçu.

${ }^{31}$ CICHORSTI, Gabriela. Entrevista concedida em 12/12/2014 a Paola Stefanutti, Foz do Iguaçu.

${ }^{32}$ CICHORSTI, Gabriela. Entrevista concedida em 12/12/2014 a Paola Stefanutti, Foz do Iguaçu.

${ }^{33}$ CICHORSTI, Gabriela. Entrevista concedida em 12/12/2014 a Paola Stefanutti, Foz do Iguaçu.
} 
do Pescado", lembram que a salga é um processo que remete à civilização egípcia, percorrendo a história alimentar da humanidade:

Com a descoberta de novos processos de conservação, nomeadamente a refrigeração e congelamento, e com o desenvolvimento de produtos mais ajustados às atuais preferências dos consumidores, o processo de salga de pescado tem perdido importância. (NUNES; PEDRO, 2011, p.157).

Iracema, gaúcha, com setenta anos, chegou em Foz do Iguaçu em 1961, vindo na onda migratória da Colonização do Oeste do Paraná. Seus rastros de comida foram pirão, mandioca, massa e "arrozfeijão". Coelho, com setenta e dois anos, chegou em 1978, e migrou por motivos profissionais, em busca de trabalho, no canteiro de obras da Usina de Itaipu. Da memória sensorial, que tem uma relação de pertencimento e identidade temos a doce e ingênua descrição dos três pés de café. Já o casal Cecílio e Maria das Graças, com cinquenta e cinco anos e cinquenta e seis anos de idade. Eles chegaram em Foz do Iguaçu em 1989, e migraram pelo contrabando, fecharam a rampa de acesso ao Lago de Itaipu em Santa Helena. Os indícios alimentares deste casal sobre identidade foram o chimarrão e o arroz com macaúba. A quinta entrevistada é Gabriela Cichorsti, que chegou a Foz do Iguaçu em 1991, os motivos da migração não ficaram explícitos, mas pode-se supor que migraram por questões da pesca. Aliás, ela foi a única que relata ser pescadora antes da vinda à Foz do Iguaçu. Gabriela relata vestígios de identidade através do charque de peixe feito em Altônia.

\section{Metodologia}

Conforme apontado na introdução, a metodologia aplicada neste trabalho é história oral temática, sendo este um método de pesquisa que busca a ampliação de conhecimento sobre o passado, não sendo "um fim em si mesmo, e sim um meio de conhecimento" (ALBERTI, 2005 p. 29), tendo uma abordagem efetivamente relevante para a investigação que se pretende realizar.

A opção pela metodologia da história oral foi fortemente influenciada, pelo autor Cardin (2014) , quando o sujeito entrevistado retrata suas aflições, dúvidas, inquietudes, omissões, frustrações, suspiros, orgulho, sensações únicas, podendo até proporcionar momentos ao leitor, de se imaginar no local da entrevista, ou da conversa, (como este autor nomeia seus diálogos com o sujeito) como se estivesse participando ou quase entrevistando junto com o pesquisador. Este tipo de método estabelece uma relação mais humanística entre sujeito e pesquisador, fornecendo subsídios para uma compreensão, através de narrativas faladas e/ou omitidas, adicional e algumas vezes até opostas à história oficial. Sendo estas narrativas vivas, compostas de pessoas reais, que possuem memórias, que sentem, presenciam, narram e vivem histórias. 


\section{Considerações Finais}

Entende-se, portanto, que esta escrita trata de memórias individuais de cinco pescadores que se assemelham e, ao mesmo tempo, se distanciam, sendo pescadores que têm atividades e percepções mais ou menos comuns. Fazendo um levantamento do perfil dos cinco entrevistados, tem-se que são homens e mulheres, casados e viúvos, na faixa etária entre cinquenta e cinco a setenta e dois anos. Suas naturalidades são diversas, dentre gaúchos, paulistas ou paranaenses, porém se faz a importante ressalva de que nenhum deles é natural de Foz do Iguaçu, isso expressando a importância da migração que ocorreu no período para o Oeste do estado do Paraná. São, portanto, pescadores que chegaram ao município entre 1971 e 1991, que dedicaram suas vidas, ou uma grande parte delas, à atividade pesqueira pescadores de rio, pescadores de lago, pescadores de peixes, pescadores da vida. Reforça-se que há ainda outras memórias de outros pescadores de Foz do Iguaçu, isso para futuras pescas.

Estabelece-se ainda uma relação da comida como identidade e, nesta mesma discussão da comida como identidade, tem-se a distinção da comida e do alimento. $\mathrm{O}$ alimento constitui o ato de alimentar-se, nutrir-se. Enquanto comida, envolve todo o contexto sociocultural à mesa, o que comer, quando comer, aonde comer, porque comer, o jeito de comer, o modo de preparo, os acompanhamentos, os acompanhantes, o tempo, e toda a ritualização à mesa. Os comensais comem cultura. Conscientes ou não deste processo. Comer não é um ato neutro, assim como a comida não o é. A escolha destes vem carregada de significados e simbologias culturais, uma comida culturalizada.

A comida de Foz do Iguaçu não é a comida da região, mas a comida das regiões, que é uma comida além da fronteira, além da fronteira estadual ou nacional, que mistura ingredientes, saberes, sabores, temperos, aromas, texturas, consistências, técnicas de diferentes origens, de diferentes migrações, histórias, modos de vida e memórias alimentares peculiares. É uma comida carregada de simbologias, uma comida híbrida, uma comida fronteiriça, em um caldeirão cultural comestível.

Se o método de pesquisa da história oral temática busca a ampliação de conhecimento sobre o passado, como sinaliza Alberti (2005), esta pesquisa cumpre o papel de ampliar o conhecimento sobre as memórias destes pescadores, suas migrações e seus vestígios alimentares. Essas reflexões de saberes tradicionais, sabores e predileções, são de fundamental importância para o registro das memórias alimentares dos pescadores. Espera-se ainda contribuir com memórias em Foz do Iguaçu e que as informações e reflexões dessa pesquisa possam fomentar e fundamentar trabalhos futuros sobre migração e alimentação na localidade. 


\section{Referências Bibliográficas}

ALBERTI, Verena. Manual de história oral. 3. ed. Rio de Janeiro: FGV Editora, 2005.

ALÍCIA ELBULLITALLE. Léxico científico-gastronômico: as chaves para entender a cozinha de hoje. Tradução: Sandra Trabucco Venezuela. São Paulo: Editora Senac São Paulo, 2008 .

BOSI, Ecléa. Memória e sociedade: lembranças de velhos. 3.ed. São Paulo: Companhia das Letras, 1994.

CARDIN, Eric Gustavo. La historia de una vida en situación de frontera: migración, superación y trabajo en el "circuito sacoleiro". Revista de Estudios Sociales, núm. 48, eneroabril, 2014, pp. 100-109. Universidad de Los Andes. Bogotá, Colombia. Disponível em: <http://www.redalyc.org/pdf/815/81530018008.pdf>. Acesso em: 25 abr. 2014.

CASCUDO, Luís da Câmara. História da alimentação no Brasil. 3.ed. São Paulo: Global, 2004.

COLOMBO, Leonir Olderico. No rastro do burro: memórias e discursos do "colono posseiro". Foz do Iguaçu, PR: Canal 6, 2015.

CORÇÃO, Mariana. Memória gustativa e identidades: de Proust à cozinha contemporânea. Disponível em: <http://www.historiadaalimentacao.ufpr.br/grupos/textos/memoria_gustativa.PDF>. Acesso em: 23 fev. 2015.

DAMATTA, Roberto. O que faz o brasil, Brasil?. Rio de Janeiro:Editora Rocco, 1986.

FISCHLER, Claude. El (h)omnívoro: El gusto, la cocina y el cuerpo. Tradução: Mario Merlino. BARCELONA: Anagrama, 1995.

GARCIA, Rosa Wanda Diez. Alimentação e saúde nas representações e práticas alimentares do comensal urbano. In: CANESQUI, Ana Maria; GARCIA, Rosa Wanda Diez. (Org.). Antropologia e nutrição: um diálogo possível. Rio de Janeiro: Editora FIOCRUZ, 2005. p. 211-225. 
GIARD, Luce. Artes de nutrir. In: CERTEAU, Michel de; GIARD, Luce; MAYOL, Pierre. A invenção do cotidiano: 2. Morar, cozinhar. Tradução: Ephraim Ferreira Alves e Lúcia Endlich Orth. 7 ed. Petrópolis, RJ: Vozes, 2008. p. 211-332.

GINZBURG, Carlo. Mitos, emblemas, sinais: morfologia e história. Tradução: Federico Carotti. São Paulo: Companhia das Letras, 1989.

GINZBURG, Carlo. O queijo e os vermes: o cotidiano e as ideias de um moleiro perseguido pela Inquisição. Tradução: Maria Betânia Amoroso. 8 ed. São Paulo: Companhia das Letras, 2006.

GREGORY, Valdir. Fronteiras, migrações e imaginários. In: VANDERLINDE, Tarcísio (Org.). Fronteiras: impactos socioambientais na Terra Prometida. Porto Alegre, RS: Evangraf, 2011.p.17-27.

GREGORY, Valdir. Fronteiras múltiplas: narrativas sobre os sertões do Paraná. In: COLOGNESE, Silvio Antônio; CARDIN, Eric Gustavo (Orgs.). As ciências sociais nas fronteiras: teorias e metodologias de pesquisa. Cascavel, PR: JB, 2014.p.183-214.

GREGORY, Valdir. Os eurobrasileiros e o espaço colonial:migrações no oeste do Paraná (1940 - 70). Cascavel, PR: EDUNIOESTE, 2002.

KINUPP, Valdely Ferreira; LORENZI, Harri. Plantas alimentícias não convencionais (PANC) no Brasil: guia de identificação, aspectos nutricionais e receitas ilustradas. São Paulo: Instituto Plantarum de Estudos da Flora, 2014.

KLEIN, Herbert S. Migração internacional na História das Américas. In: FAUSTO, Boris (Org.). Fazer a América. São Paulo: Editora da Universidade de São Paulo, 1999.

MELCHIOR, Kleber Dreicy. A migração dos mortos: remanejamento de cemitérios na região do Lago de Itaipu. 2012. 76 f. Dissertação (Mestrado em Sociedade, Cultura e Fronteiras) Universidade do Oeste do Paraná, Foz do Iguaçu, PR.

MINISTÉRIO DA PESCA E AQUICULTURA - MPA. Pesca Artesanal. Disponível em: <http://www.mpa.gov.br/index.php/pesca/artesanal>. Acesso em: 14 fev. 2014.

NADALIN, Sérgio Odilon. Paraná: ocupação do território, população e migrações. Curitiba, PR: SEED, 2001.p. 9.

NUNES, Maria Leonor; PEDRO, Sónia. Tecnologias tradicionais: salga do pescado. In: GONÇALVES, Alex Augusto (Editor) Tecnologia do pescado: ciência, tecnologia, inovação e legislação. São Paulo: Atheneu, 2011. p. 156-165. 
POLLAK, Michael. Memória, esquecimento, silêncio. Estudos Históricos, Rio de Janeiro, v. 2, n. 3, p. 3-15, 1989.

PONS, Sílvia Carrasco i. Pontos de partida teórico-metodológicos para o estudo sociocultural da alimentação em um contexto de transformação. CANESQUI, A. M.; GARCIA, R.W.D. (Org.). Antropologia e nutrição: um diálogo possível. Rio de Janeiro: Editora FIOCRUZ, 2005.p. 101-126.

RENAN, Ernest. O que é a nação? Plural; Sociologia, USP, São Paulo, I. Sem.1997. Disponível em: <http://www.fflch.usp.br/ds/plural/edicoes/04/traducao_1_Plural_4.pdf>. Acesso em: 10 out. 2013.

TEDESCO, João Carlos. Ruminantes de memórias: sentimentos, experiências e silêncios deliberados. História: Debates e Tendências, v. 13, n. 2, p. 343-353, jul./dez. 2013.

\section{Entrevistas}

ANDRADE, Iracema Berlanda de. Entrevista concedida em 1\%/12/2014 a Paola Stefanutti, Foz do Iguaçu.

CICHORSTI, Gabriela. Entrevista concedida em 12/12/2014 a Paola Stefanutti, Foz do Iguaçu.

PANSTEIN FILHO, Cecílio e PANSTEIN, Maria das Graças Ramos da Cruz. Entrevista concedida em 25/11/2014 a Paola Stefanutti, Foz do Iguaçu.

SOUZA, Antônio de. Entrevista concedida em 22/12/2014 a Paola Stefanutti, Foz do Iguaçu. 